\title{
On the dependence of ENSO simulation on the coupled model mean state
}

\author{
L. Magnusson $\cdot$ M. Alonso-Balmaseda $\cdot$ F. Molteni
}

Received: 12 June 2012/ Accepted: 16 October 2012/Published online: 30 October 2012

(C) The Author(s) 2012. This article is published with open access at Springerlink.com

\begin{abstract}
Systematic model error remains a difficult problem for seasonal forecasting and climate predictions. An error in the mean state could affect the variability of the system. In this paper, we investigate the impact of the mean state on the properties of ENSO. A set of coupled decadal integrations have been conducted, where the mean state and its seasonal cycle have been modified by applying flux correction to the momentum-flux and a combination of heat and momentum fluxes. It is shown that correcting the mean state and the seasonal cycle improves the amplitude of SST inter-annual variability and also the penetration of the ENSO signal into the troposphere and the spatial distribution of the ENSO teleconnections are improved. An analysis of a multivariate PDF of ENSO shows clearly that the flux correction affects the mean, variance, skewness and tails of the distribution. The changes in the tails of the distribution are particularly noticeable in the case of precipitation, showing that without the flux correction the model is unable to reproduce the frequency of large events. For the interannual variability the momentum-flux correction alone has a large impact, while the additional heat-flux correction is important for the teleconnections. These results suggest that the current forecasts practices of removing the forecast bias a-posteriori or anomaly initialisation are by no means optimal, since they can not deal with the strong nonlinear interactions. A consequence of the results presented here is that the predictability on annual time-ranges could be higher than currently achieved. Whether or not the correction of the model mean state by some sort of flux correction leads to better forecasts needs to be addressed. In any case,
\end{abstract}

L. Magnusson $(\square) \cdot$ M. Alonso-Balmaseda $\cdot$ F. Molteni ECMWF, Shinfield Park, RG2 9AX Reading, United Kingdom e-mail: Linus.Magnusson@ecmwf.int flux correction may be a powerful tool for diagnosing coupled model errors and predictability studies.

Keywords ENSO - Flux correction - Seasonal forecast · Decadal forecast

\section{Introduction}

Systematic model error is a difficult problem for seasonal forecasting and climate predictions. Systematic model error means that the climatology of the model is different from the observed climatology, in the sense of the mean climate (the mean of a variable over a long period) and/or the variability around the mean state. In a nonlinear system, the different moments of the climatology are linked, and errors in the mean state could affect the variability of the system. In this report we will investigate the effect of the mean state focusing on the simulation and forecast of El NiñoSouthern Oscillation (ENSO) related variability.

ENSO is the strongest known mode of the inter-annual variability in the climate system. ENSO is primarily affecting the tropical sea-surface temperature in the mid and eastern equatorial Pacific, but has an impact on the atmospheric circulation on a global scale. Therefore it is crucial that a forecasting model for seasonal time-scales can simulate the behaviour of the phenomena. For climate predictions it is important for models to simulate the ENSO in order to capture the internal variability of the climate system and a possible change in variability due to increased greenhouse gas concentrations in the atmosphere.

The building up of an El Niño could be explained by Bjerknes positive ocean-atmosphere feedback process (Bjerknes 1969). The feedback process consists of the following steps: (1) a positive SST anomaly in the eastern 
Pacific (2) reduces the SST gradient in the basin. A reduced SST gradient in the basin leads to (3) a reduced Walker circulation, which (4) gives weaker trade winds. The trade winds drive the ocean circulation and weaker winds give (5) rise to a reduced upwelling of cold water in the eastern part of the basin, which (1) strengthen the positive SST anomaly in the eastern part of the basin. If systematic model errors affect any of the components in the feedback loop, it could lead to erroneous simulations of ENSO events.

The systematic error of coupled models in the tropical Pacific has been discussed extensively in the literature. Different models show different types of errors. Those most common in coupled models consist of a warm bias off the eastern coast, attributed to the lack of sufficient upwelling and/or stratocumulus clouds; a cold bias associated with the cold tongue (either due to intensity error or geographical location error); the so-called double ITCZ, characterised by a too meridionally symmetric precipitation pattern, and the deficient representation of the intraseasonal oscillation. Several studies have argued that both errors in the mean and intra-seasonal variability can affect the representation of ENSO (Kessler and Kleeman 2000; Vitart et al. 2003; Lengaigne et al. 2004; Eisenman and Tziperman 2005; Balmaseda and Anderson 2009; Guilyardi et al. 2009). The interaction between model mean state and variability has been discussed in e.g Jin et al. (2008), Guilyardi (2006), Manganello and Huang (2009) and Spencer et al. (2007). While Jin et al. (2008) discuss the issue in the context of different models, Manganello and Huang (2009) discuss it in the context of the use of flux correction. In Guilyardi (2006), the SST variability of several climate models was compared and a large diversity is found in the tropical Pacific, both regarding amplitude and location of the variability. It was found that models with a strong seasonal cycle had a weak ENSO amplitude and that a weak seasonal cycle allowed a seasonal phase lock, with the ENSO amplitude peaking in boreal winter. The sensitivity of ENSO to flux correction has also recently been discussed in Kröger and Kucharski (2011) and Pan et al. (2011). By adjusting the surface fluxes, the mean state and the seasonal cycle can be corrected and these studies show a large sensitivity to the mean state on the ENSO variability.

In this study we will use flux correction to exemplify the interaction between mean state errors and variability using a version of the ECMWF coupled model on the decadal time scale, which for this version has a wind bias in the tropical Pacific. The correction will be applied to both the mean and the seasonal cycle of the momentum and heat fluxes, and its impact on the ENSO variability will be investigated. The flux corrected experiments will be compared to a set of reference simulations that do not use any flux correction. The focus will be on the tropical Pacific and the ability to model the ENSO variability. In a companion paper (Magnusson et al. 2012) the effect on the forecast quality is discussed. We will put this discussion in the context of the different forecast strategies. The results from this study should not be seen as universal but dependent on the flavour of the systematic error in the current model.

\section{Reference data and model and experimental setup}

\subsection{Model}

The model used for this study is the ECMWF IFS model (version 36r1) coupled with the NEMO ocean model version 3.0 (Madec 2008). The resolution for the experiments is in the atmosphere $\mathrm{T}_{L} 159$ (which corresponds to an horizontal resolution of $150 \mathrm{~km}$ ) and 91 vertical levels. For the ocean the ORCA1 grid is used, which has a 1 degree horizontal resolution with meridional refinements in the tropics. Instead of using a dynamical sea-ice model, the seaice is sampled from historical data. The sea-ice is randomly selected from any of the 5 years before the simulation year, for details see Molteni et al. (2011). The perturbations for the ensemble members are generated by using the stochastic perturbed physics tendency (SPPT) scheme (Palmer et al. 2009) in order to simulate model uncertainties in the atmosphere. The model runs include increased green-house gases following observed values. Tropospheric and stratospheric aerosols are included in the model only as fixed climatologies, so no account is taken of volcano eruptions and changes in anthropogenic "pollution".

\subsection{Experiments}

Tables 1 (model climate simulations) and 2 (decadal experiments) show a summary of the experiments that have been run for this study. To obtain an estimate of the model climate, 3-member ensembles initialised in 1965, 1975 and 1985 have been run for 25 years (referred to as Control in what follows). These simulations are used to calculate the model climate for the anomaly initialisation (see below), as well as for diagnostics. An additional set of 25-year (1965, 1975) and 23-year (1985) forecasts was conducted where the sea-surface temperature (SST) was strongly constrained to observations by a relaxation technique. This methodology has been used by Keenlyside et al. (2008) and Balmaseda and Anderson (2009) among others, to initialise coupled models. The resulting atmospheric fields are equivalent to those obtained by AMIP integrations (Atmospheric only simulation forced by observed SST). Results from the 1965 and 1975 simulations are used for 
Table 1 Experiment configurations for model climate estimations and fluxcorrection calculations

Table 2 Experiment configurations for decadal forecasts

\begin{tabular}{lllll}
\hline Name & $\begin{array}{l}\text { Forecast } \\
\text { length (years) }\end{array}$ & Members & Flux correction & $\begin{array}{l}\text { Number } \\
\text { initial dates }\end{array}$ \\
\hline Control & 25 & 3 & None & 3 \\
StrongRelax & $25(23)$ & 3 & None & 3 \\
WeakRelax & $25(23)$ & 3 & Momentum & 2 \\
\hline
\end{tabular}

\begin{tabular}{llllll}
\hline Name & $\begin{array}{l}\text { Forecast } \\
\text { length (years) }\end{array}$ & Members & Initialisation & Flux correction & $\begin{array}{l}\text { Number } \\
\text { initial dates }\end{array}$ \\
\hline NOcorr & 10 & 7 & Anomaly & None & 9 \\
Ucorr & 10 & 3 & Full & Momentum & 9 \\
UHcorr & 10 & 7 & Full & Heat and momentum & 9 \\
\hline
\end{tabular}

the calculation of the momentum-flux correction (see below). The SST data used for the relaxation is the same as for ERA-40 up to 1981 and after that Reynolds version 2 (Reynolds et al. 2002).

Decadal (10-year) forecasts have been initialised every fifth year with the first started in November 1960 and the last in November 2000 (1960, 1965, 1970, 1975, 1980, 1985, 1990, 1995 and 2000).

In all experiments the atmospheric initial conditions are from the ERA-40 (Uppala et al. 2005) until 1989 and from ERA Interim (Dee et al. 2011) therafter (at productiontime of the experiments ERA Interim was only available from 1989). The ocean initial conditions are from the NEMOVAR-COMBINE (Balmaseda et al. 2010) ocean reanalysis. The ocean reanalysis uses fluxes from the ERA-reanalyses as well as sub-surface observations.

\subsection{Reference climate}

As a reference climatology for the ocean, the NEMOVARCOMBINE reanalysis will be used, which is available for the period 1958-2009 and the operational oceanic reanalysis for ECMWF S4 for the second half of 2009 and 2010.
For the atmospheric diagnostics, we will mainly limit the evaluation to the extended ERA Interim period (1979-2010). For the precipitation climatology, data from Global Precipitation Climatology Project GPCP version 2 (Huffman et al. 2009) will be used as well as ERA Interim.

\subsection{Model climate}

As an introduction to the systematic errors in the nearsurface atmosphere, Fig. 1 shows the bias in the sea-surface temperature (SST) from the 25-year control simulations. The model climate has been computed by aggregating together year 14-23 from from each of the three control simulations, which in total cover the period 1979-2008: 1979-1988 from the forecast initialised in 1965 , 1989-1998 for the forecast initialised in 1975 and 1999-2008 from the forecast initialised in 1985. The bias has been calculated with respect to the ERA Interim reanalysis between 1979 and 2008. In general, the model is too cold with a global bias of $1.0 \mathrm{~K}$. The cold bias is present all over the tropics and extra-tropics, while the Southern Ocean exhibits a warm bias. The structure of the bias leads to a weakening of the meridional temperature
Fig. 1 Bias in sea-surface temperature for the long control simulation, forecast year 14-23

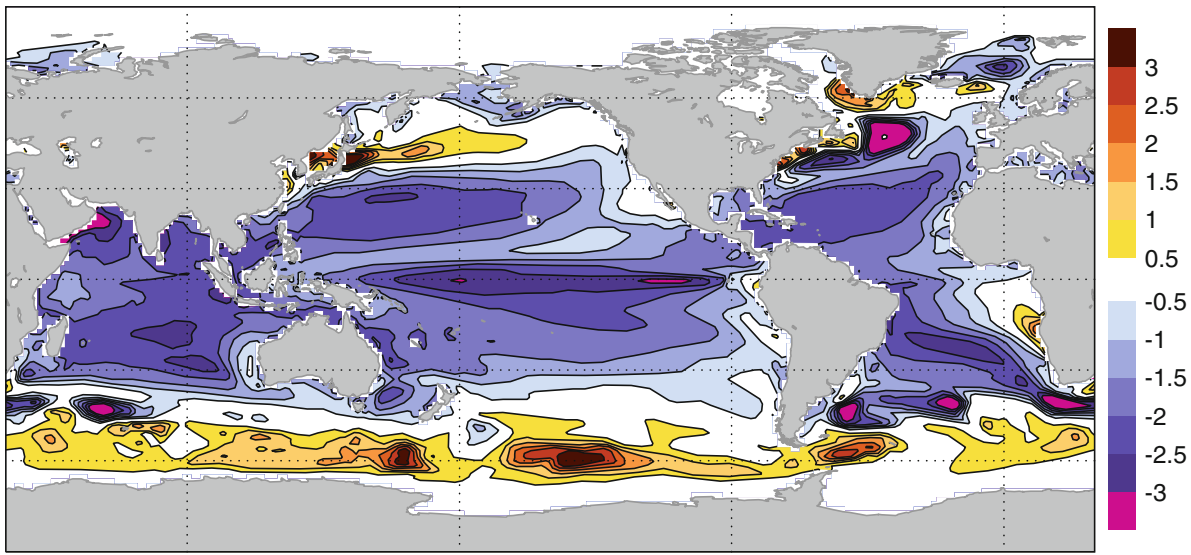


gradient. In the tropical Pacific an enhanced cold bias is present, which will be in the focus for this study.

Figure 2a shows the bias in the zonal component of the 10-metre wind speed for the long control simulation, calculated for the same period as the sea-surface temperature bias. Generally, the bias is less than $1 \mathrm{~m} / \mathrm{s}$, with a few exceptions. In the Southern Ocean the westerlies are reduced over the southern edge of Antarctic Circumpolar Current. The largest bias appears in the western tropical Pacific, with values of up to $3 \mathrm{~m} / \mathrm{s}$. The bias is of the same order of magnitude as the wind speed in the reanalysis, meaning that the wind speed in the model is about twice the reanalysis value. The zonal wind in the western tropical Pacific has a large influence on the ENSO, and it also impacts the state of the thermocline and SST.

Figure $2 \mathrm{~b}$ shows the same as Fig. 2a but for the experiment using a strong relaxation to the observed SST. By constraining the SSTs, the wind bias is reduced in the Equatorial Pacific and Indian Ocean. The impact of SST is especially large in the western part of the basin where the bias is reduced by 50 . This illustrates clearly the positive feedback between SST and wind bias in the coupled model. It also shows that the atmospheric model has a strong wind bias, per se. The bias in the tropical Pacific in the uncoupled model is developing early in the forecast and is also found in evaluation of the first days of medium range weather forecasts with the same model. The error in the wind over most of the Antarctic circumpolar Current seems to be of oceanic origin, since it largely disappears when the atmosphere is forced by observed SST.

\subsection{Flux correction}

Model improvement is the ultimate way of reducing model biases. As a temporary solution until the problems in the model are detected and solved, one could compensate for the systematic errors by applying empirical corrections. One specific correction is the so-called flux correction, applied only in the coupling between the atmosphere and the ocean. The use of different flavours of flux correction have recently been discussed in Spencer et al. (2007), Manganello and Huang (2009), Pan et al. (2011) and

\section{(a)}

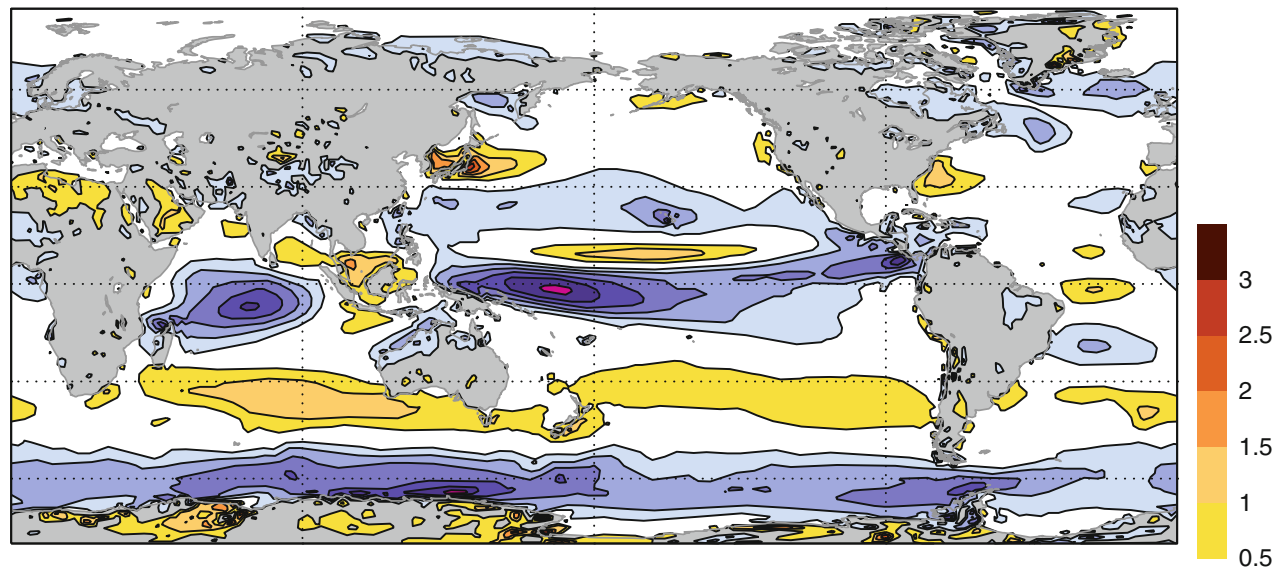

(b)

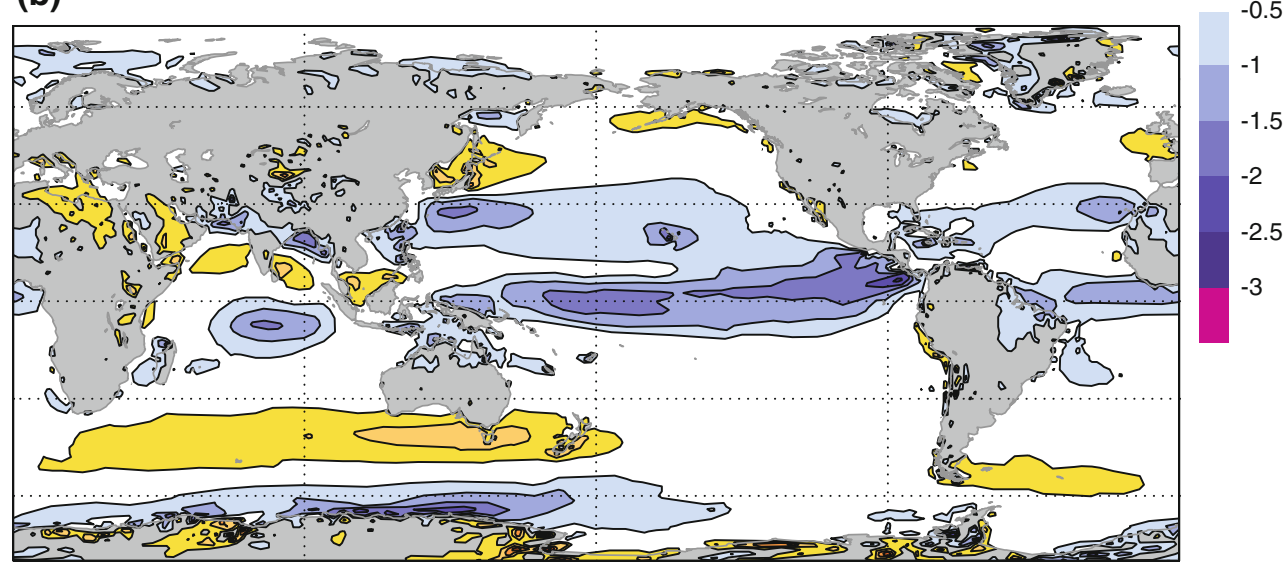

Fig. 2 Bias in zonal 10-m wind. Forecast year 14-23. a Coupled model, b simulation using strong SST relaxation 
Kröger and Kucharski (2011). In the experiments presented here, the flux correction is applied on the fields passed from the atmospheric model to the ocean model. In order to represent the seasonal cycle of the systematic errors, correction fields have been estimated for each calendar month in order to correct also the seasonal cycle. The monthly flux correction climatology is then linearly interpolated in time before applying to the coupling interface for a given day.

One could expect that SST errors originate both from the heat flux to the ocean and the momentum flux. As seen in the previous section (Fig. 2a, b), a wind bias is present in the model run with strong relaxation to observed SSTs. Our hypothesis is that the SST bias could be reduced by reducing the wind bias. However, the SST error may also have other causes, like ocean-atmosphere heat exchange, among others. Therefore, the flux correction strategy applied here deals both with errors in the momentum and heat flux.

The flux correction has been calculated in two steps. Firstly, the strong SST relaxation simulations initialised in 1965 and 1975 have been used in order to calculate the wind stress errors when the SST is constrained to the reanalysis (see Fig. 2b). The momentum-flux correction has been calculated as the difference between the StrongRelax forecasts and the surface stresses from the reanalysis. The first 5 years of each simulation have not been used in order to let the atmospheric model drift. In a second step, a set of 25-year forecasts (WeakRelax) has been run applying the momentum-flux correction and a weak SST-relaxation $(40 \mathrm{~W} / \mathrm{K})$, in order to calculate the heat-flux correction required to correct the coupled SST when the momentum-flux correction applied. The SST relaxation terms from the last 20 years of these runs are used to compute the heat-flux correction monthly climatology. This strategy yields a heat-flux correction suitable to be used together with momentum-flux correction and that partly accounts for the feedback effects.

In what follows, we refer to Ucorr as the forecast using momentum-flux correction only (both on $\mathrm{u}$ and $\mathrm{v}$ components), and to UHcorr as the forecasts using both momentum and heat-flux correction.

Figure 3 shows the howmöller diagram of the monthly dependence of the zonal component momentum-flux (a) and heat-flux (b) correction for the tropical band averaged between $5^{\circ} \mathrm{N}$ and $5^{\circ} \mathrm{S}$. Global maps of the corrections could be found in Magnusson et al. (2012).

The zonal component momentum-flux (a), exhibits the strongest corrections in the tropical Pacific, with a minimum in the tropical Pacific in April and a maximum in July-August. The correction is generally positive (towards westerly stresses) reducing the too strong easterlies of the (a)

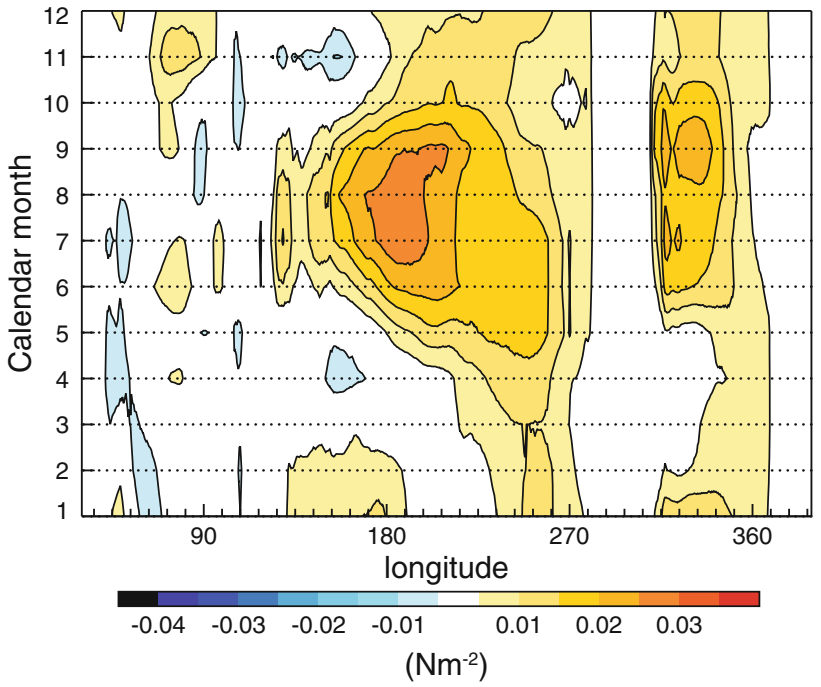

(b)

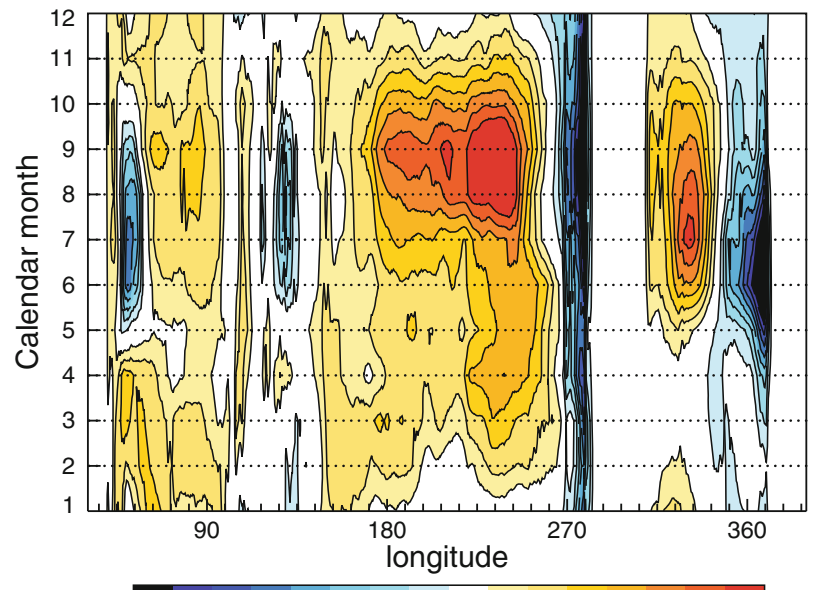

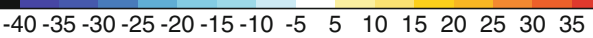

$\left(\mathrm{Wm}^{-2}\right)$

Fig. 3 Flux correction as a function of calendar month and longitude. Averaged between $5^{\circ} \mathrm{N}$ and $5^{\circ} \mathrm{S}$. a Zonal momentum-flux correction, b heat-flux correction

coupled model. The maximum is located close to the dateline $\left(180^{\circ} \mathrm{E}\right)$.

Figure $3 \mathrm{~b}$ shows the heat-flux correction required when the momentum-flux correction is applied. The strongest positive corrections are located in the eastern part of the Tropical Pacific were the cold tongue is present and where we have the strongest bias in SST. A positive correction means that heat is added to the ocean. We see in the figure that we have a seasonal variation of the required heat-flux correction. The maximum appears in September while the correction is close to 0 (or even negative) in January. At the eastern part of both the Atlantic and the Pacific negative corrections are needed due to warm biases. 


\subsection{Reference simulation}

Due to the difference in mean climate between the analysis (our best estimate of the truth) and the model, a forecast initialised from an analysis will drift torwards the model climate. A large part of the model drift can be avoided by initialising the model on its own attractor (here we define the attractor as the part of the phase space where the model/ nature evolves). This technique is referred to as anomaly initialisation and is used in several studies e.g. Schneider et al. (1999), Pierce et al. (2004) and Smith et al. (2007). In this study we use anomaly initialisation for the reference decadal integrations, so the model is initialised around its own climate.

For the initialisation, the observed anomalies (full 3-dimensional ocean field) are added to the model climate. The model climate is estimated from the 25 years control integrations, where the first 10 years of the simulations are not used in order to let the model drift to its own climatology. The climatology of the "real world" has been estimated from the ocean reanalysis, spanning the same time period used in the estimation of the model climate. This period is chosen so that the difference between the climatologies is calculated with the same change of greenhouse gases for the both. The model and analysis climatologies are calculated for the actual date for initialisation.

The reference forecasts using anomaly initialisation will be referred to as NOcorr.

\section{Results}

In this section we will exhibit the results from the different experiments in form of mean climate, inter-annual variability and effects on the atmospheric variability, focusing on ENSO. In order to evaluate the ENSO, the average SST for different areas are commonly used. In this study we will refer to Niño3 $\left(150^{\circ} \mathrm{W}-90^{\circ} \mathrm{W}, 5^{\circ} \mathrm{N}-5^{\circ} \mathrm{S}\right)$ in the eastern part of tropical Pacific; Niño3.4 $\left(170^{\circ} \mathrm{W}-120^{\circ} \mathrm{W}, 5^{\circ} \mathrm{N}-5^{\circ} \mathrm{S}\right)$ in the central part and Niño4 $\left(160^{\circ} \mathrm{E}-150^{\circ} \mathrm{W}, 5^{\circ} \mathrm{N}-5^{\circ} \mathrm{S}\right)$ in the central-western part of the basin.

\subsection{Mean climate}

Figure 4 shows the mean SST (Fig. 4a) for the tropical Pacific and a cross-section of the mean temperature along the equator (Fig. 4b). At the surface, we find the highest temperatures in the western part of the basin, with temperatures up to $30{ }^{\circ} \mathrm{C}$. Further east the temperature is colder due to upwelling of cold water. Studying the crosssection, we see that the warm pool extends vertically in the west, while the $20{ }^{\circ} \mathrm{C}$ isotherm almost reaches the surface (a)

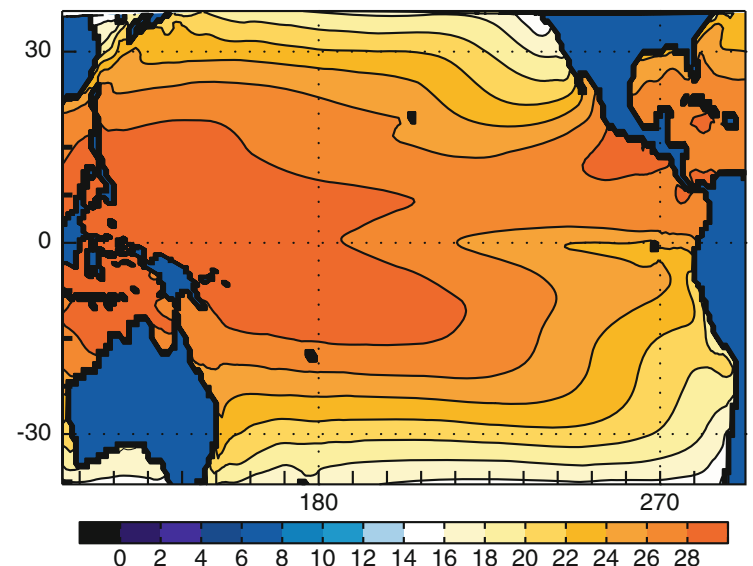

(b)

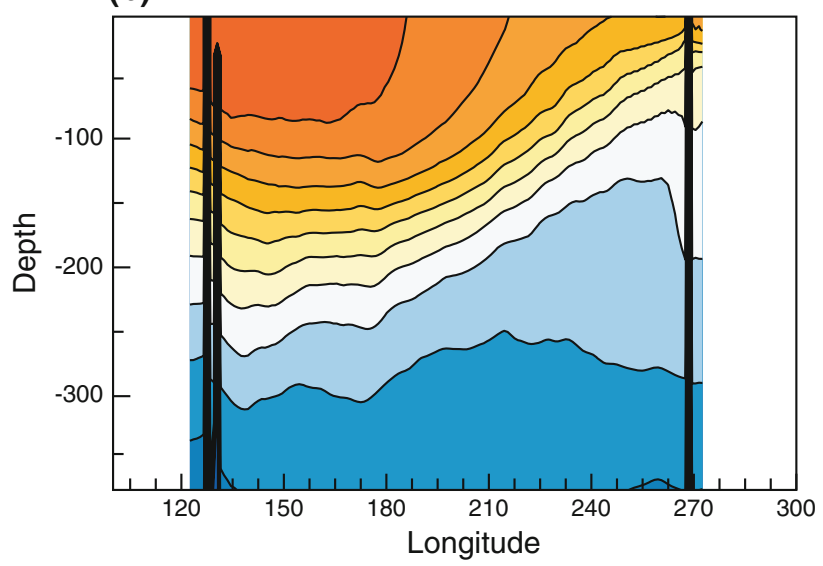

Fig. 4 Mean of the reanalysis for 1963-2010. a Mean SST, b Vertical cross-section of the temperature along the equator

in the east. This tilt of the thermocline in the mean state is not present all the time; during El Niño-events the tilt in the thermocline is strongly reduced.

Figure 5 shows the difference in SST between the NOcorr forecast and the reanalysis, yielding a measure of the model bias. To estimate the forecast climate, the decadal integrations are averaged over forecast years 3-10 for all initial dates, and the bias is calculated in respect to the analysis climate shown in Fig. 4. Generally for the tropical Pacific, we find a strong cold bias, which has its maximum along the equator. At its maximum, the bias reaches $2.5 \mathrm{~K}$. Figure $5 \mathrm{~b}$ shows a vertical cross section of the temperature bias along the equator in the Pacific for the same data as shown in Fig. 5a. As expected from the SST bias plot, a cold bias is present at the surface. On other hand we find a warm bias between 100 and $300 \mathrm{~m}$, which is strongest in the western part of the basin. This dipole structure indicates that the bias is due to an overly strong equatorial circulation (too strong upwelling in the east and a too strong downwelling in the west). The vertical structure of the 
(a)

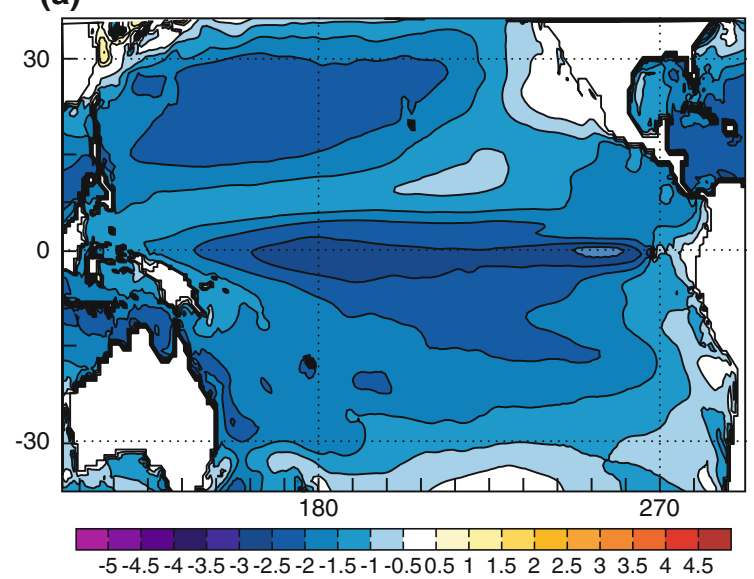

(b)

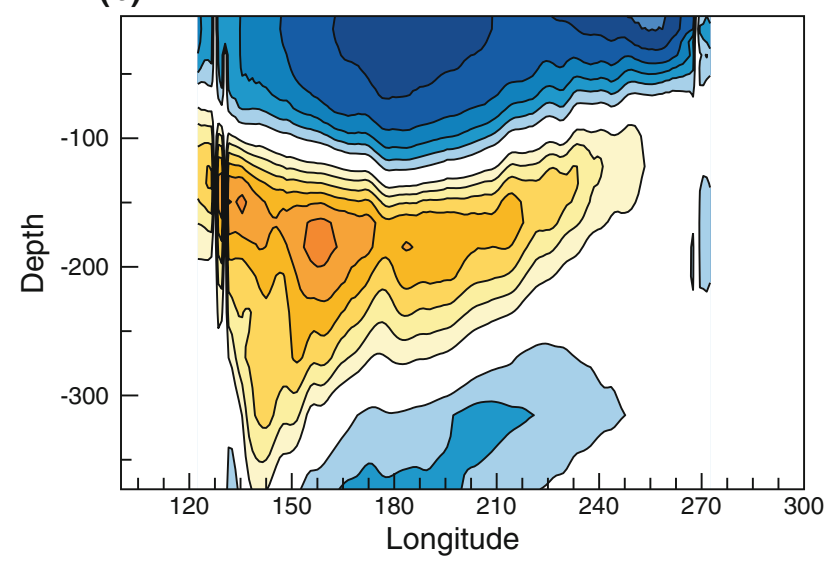

Fig. 5 Difference between the NOcorr forecast and the reanalysis for forecast year 3-10. a SST bias, b cross-section of the equatorial temperature bias

temperature bias also implies a weaker than observed vertical temperature gradient, which will result in a weaker upwelling associated cooling (or weak thermocline feedback).

Figure 6 shows the same as Fig. 5 but for the Ucorr experiment. For the SST bias (Fig. 6a), the momentum-flux correction is able to reduce the cold bias in the tropical Pacific, which indicates that the tropical bias is connected to the wind stress. Figure $6 \mathrm{~b}$ show the vertical cross-section of the ocean temperature bias for the Ucorr experiment. Comparing with the NOcorr forecast (Fig. 5b), the dipole bias structure is strongly reduced by using momentum-flux corrections, which may be explained by the fact that the flux correction reduces the easterly windstress and slows down the equatorial ocean circulation. However, there is still a bias present at the surface, and a warming of the thermocline, consistent with the too diffuse thermocline, which is a characteristic of this version of the NEMO model and observed in ocean only runs (not shown). The vertical temperature gradient in Ucorr is also (a)

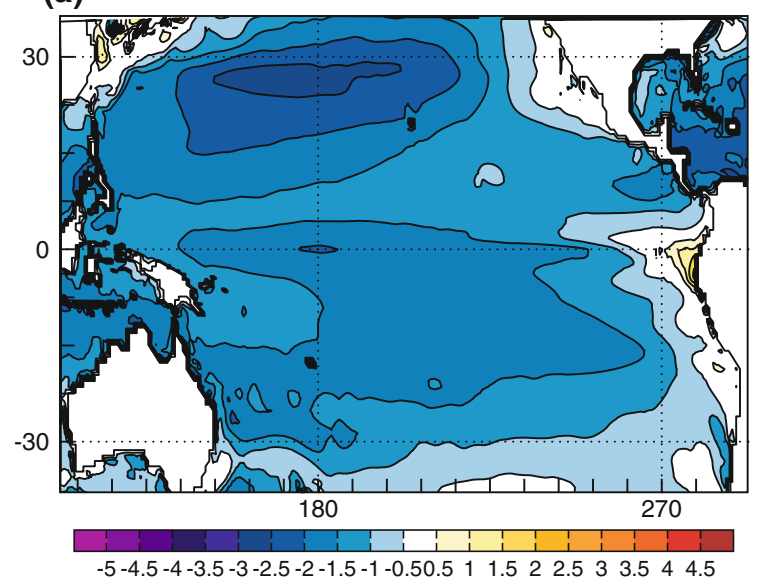

(b)

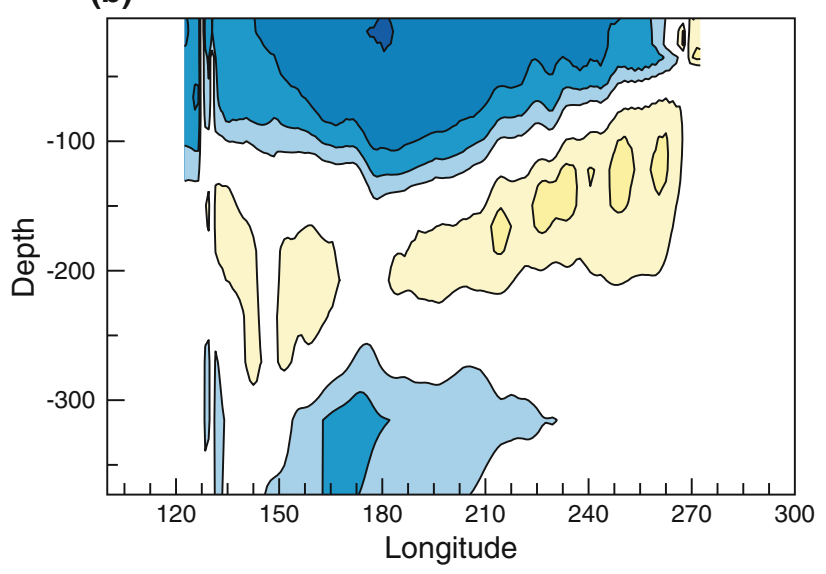

Fig. 6 Difference between the Ucorr forecast and the reanalysis for forecast year 3-10. a SST bias, b cross-section of the equatorial temperature bias

weaker than observed, but slightly improved respect to NOcorr.

Compared to the NOcorr experiment, the cold bias in the SSTs is enhanced in the mid-eastern $\left(25^{\circ} \mathrm{N}-30^{\circ} \mathrm{N}\right)$ Pacific. This change is due to the (correctly) weakening of the ocean circulation leading to a reduced northward heattransport from the tropics. Hence the bias in the transport of warm water northwards in the NOcorr experiment is compensating the cold bias. The transport bias is about $0.4 \mathrm{PW}$ in the upper $100 \mathrm{~m}$ at $20^{\circ} \mathrm{N}$ in NOcorr and is less than $0.1 \mathrm{PW}$ for Ucorr.

When using both momentum and heat-flux correction (Figure 7a), the SST bias is strongly reduced, which is the objective of the heat-flux correction. Figure $7 \mathrm{~b}$ shows the vertical cross-section of the bias for the UHcorr experiment. Comparing with the Ucorr experiment (Fig. 6b), the cold bias in the thermocline is further reduced in the west by the use of the heat-flux correction. The warming along the thermocline is increased, especially in the eastern part. This behaviour is consistent with the heat-flux correction 
(a)

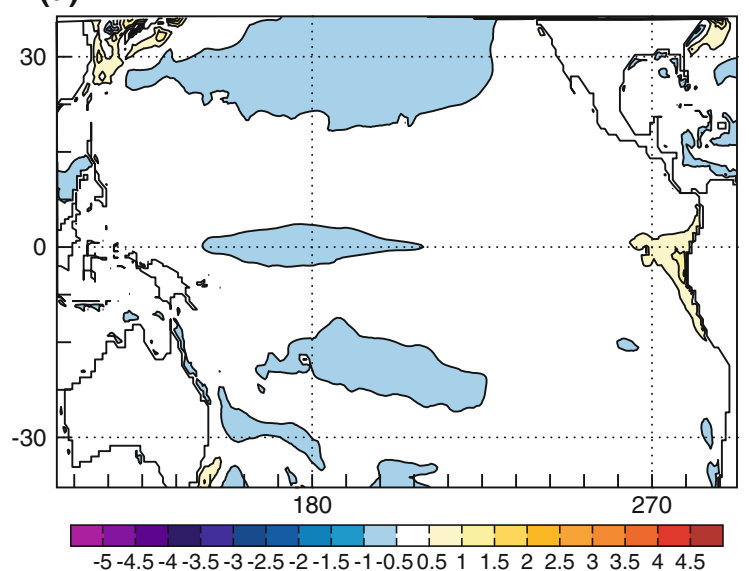

(b)

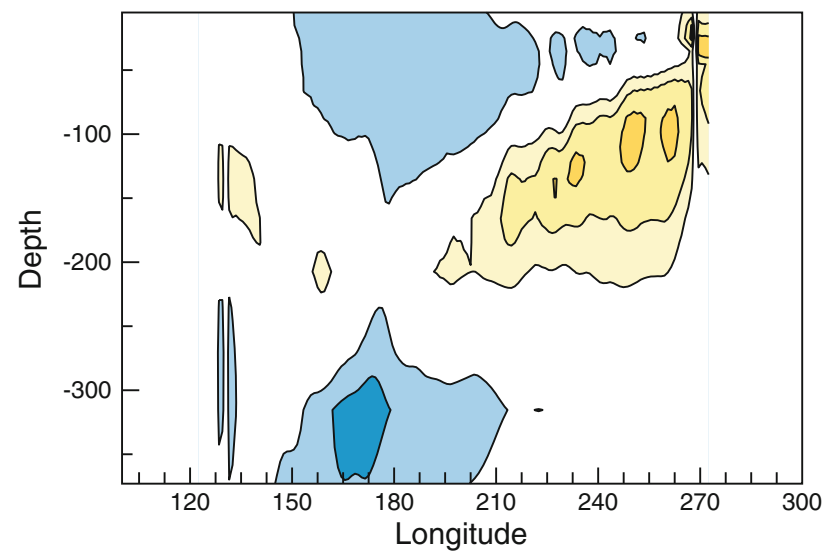

Fig. 7 Difference between the UHcorr forecast and the reanalysis for forecast year 3-10. a SST bias, b cross-section of the equatorial temperature bias

partially compensating for errors in the upper ocean vertical mixing. In the Central and Western Pacific, the vertical temperature gradient at thermocline depth in UHcorr is about right.

Figure 8 shows the monthly means of surface temperature gradient (Niño3-Niño4), zonal surface wind stress (Niño4) and the tilt of the themocline, evaluated as the difference of the depth to the $20{ }^{\circ} \mathrm{C}$-isotherm between Niño3 and Niño4. For each experiment, the data have been averaged over all initial dates and forecast year 3-10. To interpret these figures one should bear in mind that the fluxcorrection is not only correcting the mean state but also the seasonal cycle. The temperature gradient along the tropical Pacific is negative, as seen in Fig. 4, with the coldest water in the east and warmest in the west. The gradient has also a seasonal cycle with the weakest gradient occurring during boreal spring (spring relaxation), when the surface stress has a minimum. During boreal summer and autumn the temperature gradient increases due to upwelling of cold

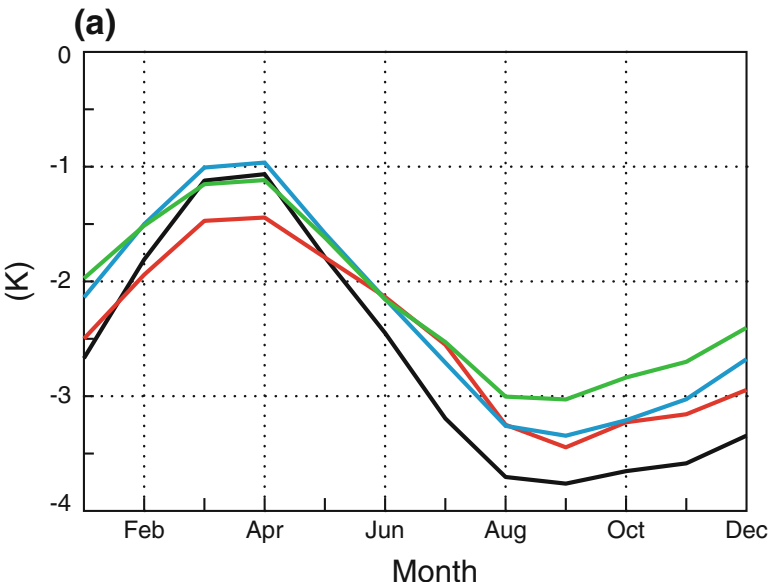

(b)

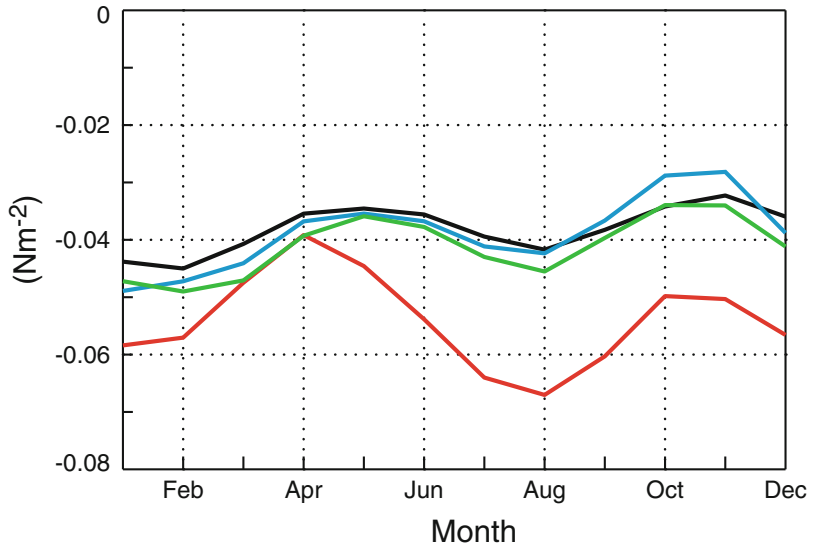

(c)

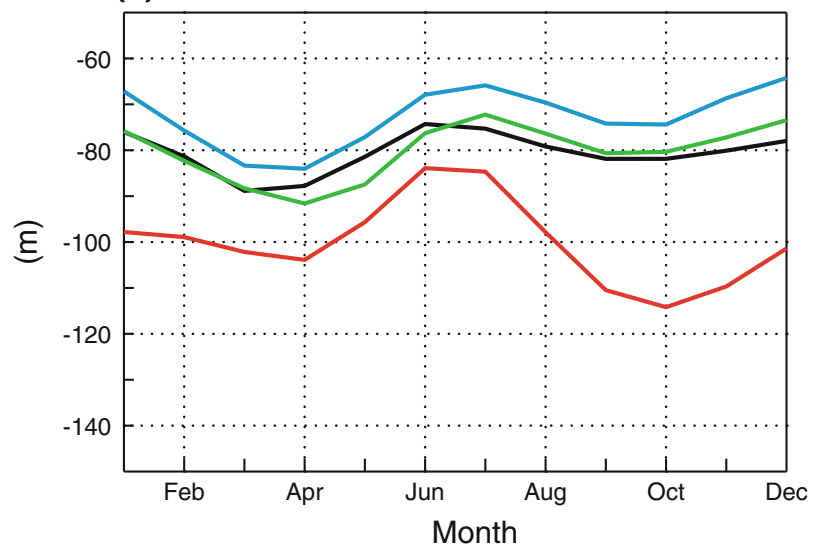

Fig. 8 Monthly means averaged for forecast year 3-10. Reanalysis (black), NOcorr (red), Ucorr (green) and UHcorr (blue). a SST difference Niño3-Niño4, b zonal wind stress Niño4, $\mathbf{c}$ thermoline depth difference Niño3-Niño4

water in the east, associated with the increase of the wind stress. This upwelling could be interrupted by El Niñoevents. The thermocline is normally tilting from east to west (deepest in the west as seen in Fig. 4a). 
In the NOcorr experiment (red) the phase of the seasonal cycle is about correct but there are errors in its amplitude. This is similar to many of the models evaluated in Guilyardi (2006). The amplitude in the seasonal cycle of the temperature gradient is lower than for the reanalysis (black), with a too strong gradient in spring and a too weak gradient in boreal autumn-winter. On other hand the wind stress shows too strong annual and semi-annual cycle, and consistently exhibits an easterly bias. A strong seasonality is also visible in the thermocline tilt, which also shows a too strong slope bias. The bias in the thermocline is closely connected to the wind stress bias and seems to lag the wind stress of about 2 months. The weak seasonality in the SST gradient in spite of the strong wind and thermocline seasonality can be a consequence of (1) the weak thermocline feedback associated to the diffused thermocline and (2) the strong western penetration of the cold tongue, which does not allow for eastward displacements of the warm pool.

In the Ucorr experiment (green), the wind stress is in much better agreement with the reanalysis (as expected). The momentum-flux correction efficiently reduces the seasonal cycle of the wind stress, as anticipated in Fig. $3 \mathrm{~b}$. We also see a much improved themocline tilt, both regarding the annual mean and the seasonal cycle, indicating the strong connection between the zonal winds and the tilt of the thermocline. The SST gradient is decreased for most times of the year, but it still has a weak seasonality: while the values of the spring relaxation are in agreement with the reanalysis, there gradient does not intensify enough later in the year.

The addition of heat-flux correction in the UHcorr experiment, where both the heat and momentum-flux correction are applied, partially improves the seasonal cycle of the SST gradient by deepening the minimum in the second half of the year, but the peak value remains underestimated. The underestimation of the SST gradient in the second part of the year goes in the opposite direction with the heat-flux correction applied (see Fig. 3a), which cools the Western Pacific and warms the Eastern Pacific. This would suggest that the flux correction applied in UHcorr may be overestimated, but it does not explain why the SST gradient is underestimated in Ucorr. One possibility is that this diagnostic is affected by the the occurrence of too strong (or too frequent) El Niño events (see below), which will decrease the gradient.

In summary, the seasonal dependent momentum-flux correction is able to correct the themocline depth and allow a weak SST gradient in the spring, but fails fails to produce the strong SST gradient in the second part of the year. The heat-flux correction further improves the seasonality of the SST gradient, deepening the boreal autumn-winter minimum, but it still underestimate the values of the strong SST gradient.

\subsection{Inter-annual variability}

An important aspect of ENSO is the amplitude of the SST anomalies. Examples of Niño3.4 SST forecasts appear in the left panels of Fig. 9. Shown are the decadal forecasts from each experiment at 4 initial dates, with a 12-month running mean applied. The NOcorr experiment (a) shows a clear offset towards cold SSTs, as expected from the cold bias discussed above. Visual inspections indicate large differences in inter-annual variability between the experiments, with weak inter-annual variability in NOcorr and the strongest variability in UHcorr. In this section we will discuss some statistical aspects of this variability. For more detailed analysis of the ENSO variability, including the evolution of individual events in phase space, see Magnusson et al. (2011).

The right panels of Fig. 9 show the lagged auto-correlation for the Niño3 SST (solid) and the lagged crosscorrelation between Niño3 SST and Niño4 SST (dashed). The reanalysis values are shown in black, and have been estimated for the period 1962-2010. The red/green/blue curves correspond to the different experiments. The lagged correlation for the decadal forecasts is the average of the lag correlation estimated for each individual ensemble member and initial date. The auto-correlation is an useful diagnostic to estimate the typical time scales of the interannual variability when limited time records are available (10 years in this case, not long enough for robust spectral analysis). The reanalysis auto-correlation shows a smooth decay, crossing the zero line at about 9 months, and showing a broad minimum at around 24 months. This is consistent with the behaviour of a damped oscillation with periods in the range 36-48 months or longer. Compared to the reanalysis, the auto-correlation of NOcorr (solid red line) decays faster within the first 4 months (sharper peak around zero), suggesting a short duration of events. After 4 months the decay time is slower, and cross the zero line after 12 months. The UHcorr experiment (blue, solid line) shows stronger (or more regular) oscillations than the reanalysis, with more defined and pronounced minimum at around 18 months, indicative of a dominant oscillation with 3-year period. The Ucorr experiment (green) shows similar decay as the UHcorr in the first months, but the minimum is not so pronounced, suggesting more irregular behaviour.

The propagating features of the variability are illustrated by the dashed lines in the right panels Fig. 9, showing the lagged cross-correlation between Niño3 SST and Niño4 SST. Positive/negative lags indicate Niño3 SST leads/lags Niño4 SST. The NOcorr experiment shows a clear peak at positive lags, indicating westward propagation of the SST anomalies. In contrast, the curve for UHcorr peaks at negative lags, consistent with the eastward propagation. 
Fig. 9 SST forecast for Niño3.4 from decadal forecasts initialised in November 1965-1995 every 10 year (coloured lines) with a 12-month running mean applied (left panels) and the autocorrelation (right panels) for Niño3 SST (solid) and for Niño3 SST to Niño4 SST (dashed). Values for the reanalysis in (black). a NOcorr, b NOcorr, c Ucorr, d Ucorr, e UHcorr, f UHcorr (a)

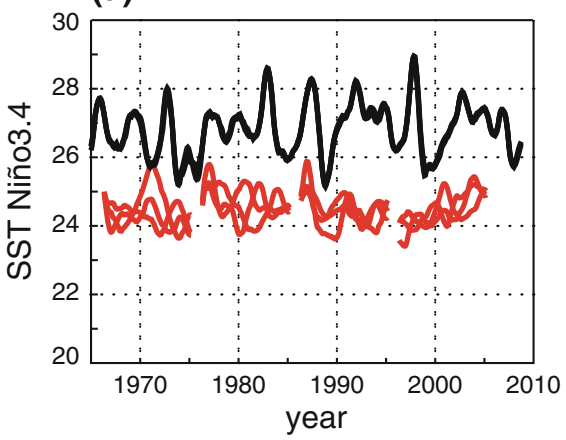

(c)

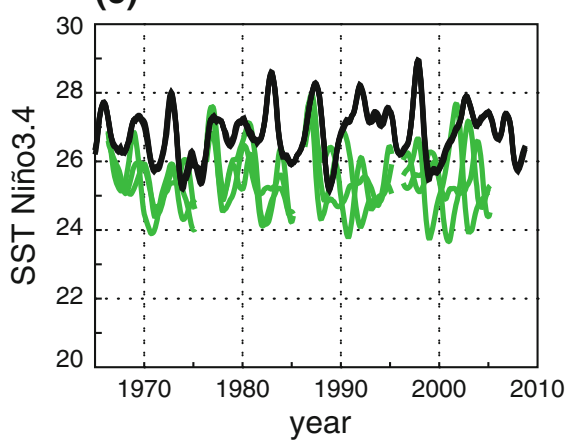

(e)

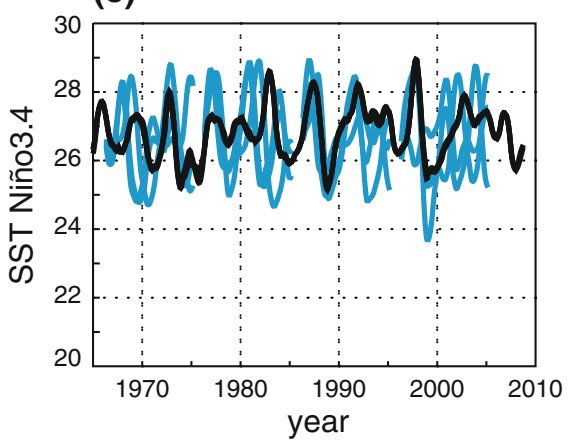

(b)

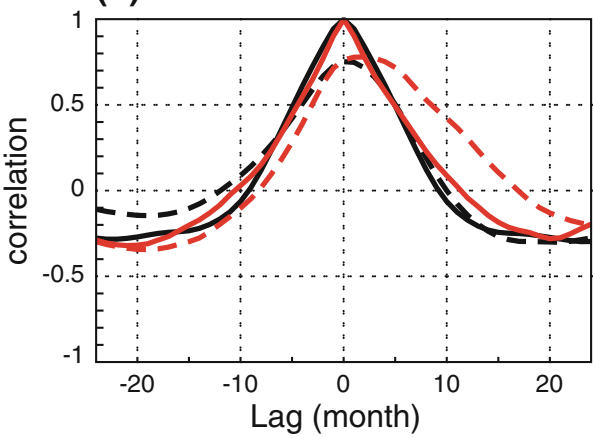

(d)

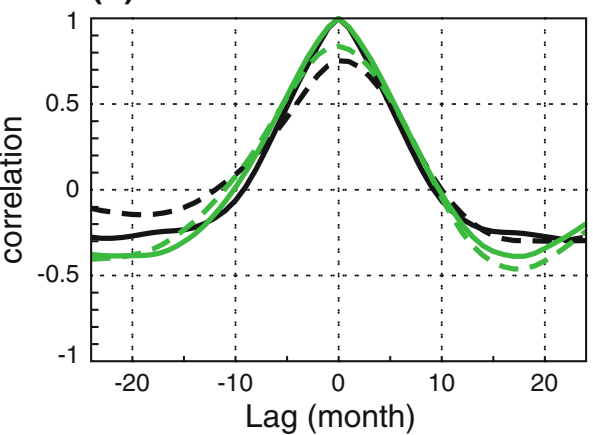

(f)

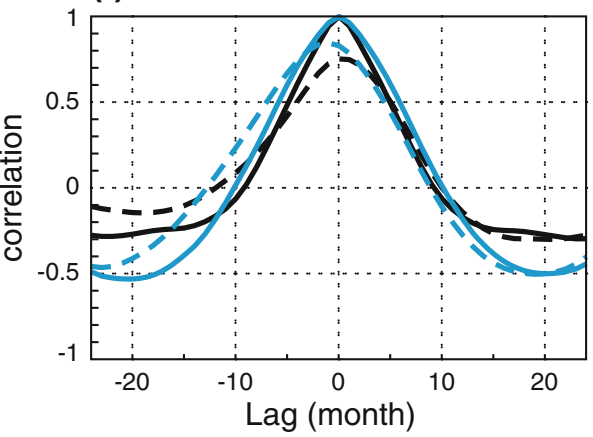

Both the reanalysis and Ucorr peak at zero lag, which could indicate stationary propagation or mixed behaviour. The latter is definitively the case of the reanalysis, with clearly westward propagating events (prior to 1975), eastward propagating events (1992-1993, 1995), and a mixture: the large 1982-1983 and 1997-1998 started as eastward propagating and continued by westward propagation.

The eastward propagation is associated with the eastward displacements of the warm pool. The warm pool is absent in the NOcorr experiment, and would explain why this experiment only shows westward propagation. The reason why the eastward propagation dominates in UHcorr is not straight forward to interpret. One possibility is that the thermocline feedback, associated to the westward propagation of the anomalies is weak compared with the warm pool effect. In any case, the variety of behaviour exhibited by the coupled experiments illustrates that delicate balanced between different mechanisms involved in the adequate representation of ENSO.

Figure 10 shows the inter-annual variability of the Niño3.4 SST as a function of calendar month. The forecast data used is for the initial dates 1960-2000 and forecast year 3-10. The reanalysis data is from 1960 to 2009. The inter-annual variability is calculated as the standard deviation with the seasonal cycle removed. For the reanalysis, means for 1960-1980 (dotted) and 1980-2000 (dashed) have also been plotted.

The general feature in the results is that the NOcorr experiment yields the lowest variability, much lower than the reanalysis. The UHcorr again is on the opposite side, showing a much higher variability than the NOcorr experiment and also higher than the reanalysis. The Ucorr experiment is in between and closest to the reanalysis, albeit underestimating the variability during the boreal 


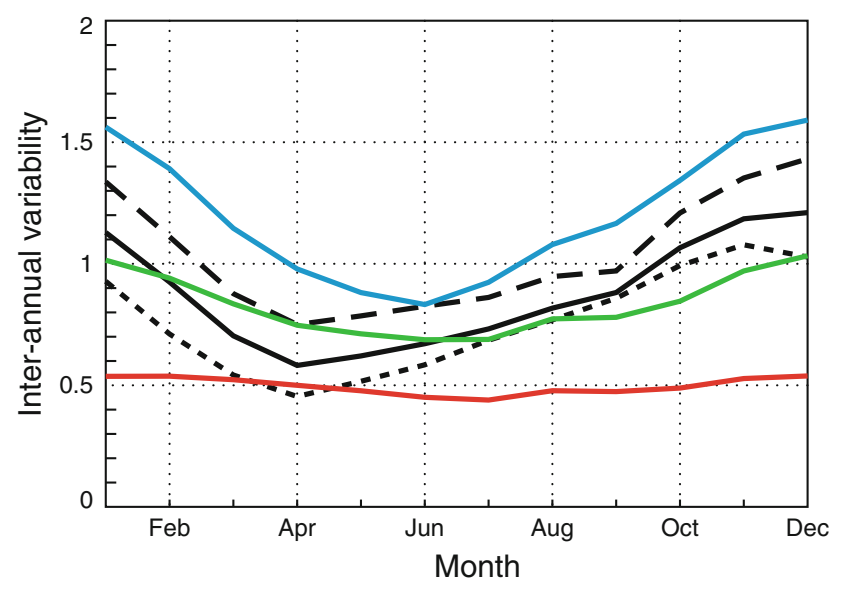

Fig. 10 SST standard deviation for Niño3.4 as a function of calendar month (seasonal cycle removed). Reanalysis 1960-2009 (black, solid), 1960-1980 (black, dotted) and 1980-2000 (black, dashed). NOcorr (red), Ucorr (green) and UHcorr (blue)

winter. Our results are in line with Guilyardi (2006), in that models with strong seasonal cycle have a weak ENSO amplitude. Fedorov and Philander (2001) relate the too strong seasonal cycle and too weak inter-annual variability with the presence of too strong wind stress, which is the case for NOcorr.

Another important aspect of the ENSO variability is the seasonal phase locking of the SST variability (Misra et al. 2007). One of the characteristics is that the ENSO events peak at the end of the calendar year, due to an interrupted upwelling of cold water. Here we see that the reanalysis has the highest variability in December as expected and the lowest in April. This phase-locking is consistent with the view that the warm events are just a disruption of the cold phase of the seasonal cycle, the warm anomaly peaking when the cold phase was due. The results for the NOcorr experiment shows a very low level of variability, and only a tiny sign of phase locking of ENSO, consistent with very strong seasonal cycle which rarely fails to occur. In the Ucorr and UHcorr experiment, the phase-locking maximum appears in December as it does in the reanalysis, which is also the season when the wind and thermocline variablity peak (not shown). The improvement of the phase-locking in the flux-corrected experiments is believed to be due to the momentum-flux correction, which weakens the stability of the coupled system during boreal autumnwinter by reducing the tilt of the thermocline and allowing the possibility of westerly wind anomalies in the Central Pacific. The weakest inter-annual variability in Ucorr and UHcorr appears in June instead of April, for reasons that are not understood, but could be related to the longer timescales for El Niño-events seen in Fig. 9.

Comparing the reanalysis data for 1960-1980 (dotted lines) and 1980-2000 (dashed) we see a large difference in the variability; the latter were a much more active period than the earlier period. There has been some discussion in the literature about decadal differences in the ENSO variability, e.g. Balmaseda et al. (1995) and Wang and Picaut (2004). The role of the decadal variability in background winds is discussed Wang and An (2002). The level of variability for the $1980-2000$ is closer to the one obtained for the UHcorr experiment, while a large difference is present between the observed in 1960-1980 and UHcorr. However, one should bear in mind the uncertainties in the observations especially before 1980, and therefore differences between the ENSO variability prior and after 1980 could partly be due to changes in the observing systems.

Figure 11 shows the spatial pattern of the inter-annual variability for the SST in the tropical Pacific (standard deviation of the inter-annual anomalies). The reanalysis (a) exhibits a variability maximum around $110^{\circ} \mathrm{W}-120^{\circ} \mathrm{W}$. The location of the maximum is well reproduced by all the experiments, but the amplitude changes substantially: there is too weak variability in NOcorr and too strong in UHcorr, with the Ucorr showing about the correct level.

Another important aspect for the development of El Niño events is the presence of westerly wind bursts in the equatorial Pacific (discussed in e.g Vitart et al. 2003). The zonal wind stress affects the tilt of the thermocline; strong easterlies give a strong tilt to the thermocline (Jin 1997a), while the westerly wind bursts (WWB) tend to reduce the tilt by deepening the thermocline in the Eastern Pacific, reducing the upwelling and producing a warming in the Eastern Pacific. This remote effect, together with a more local effect on the eastern displacement of the warm pool by zonal advection, can trigger the occurrence of ENSO events.

In order to investigate the appearance of such westerlies, the histogram of daily data for the zonal momentum-flux has been plotted for the Niño4 area (Fig. 12a). This diagnostic includes the flux correction on the wind stress. For the NOcorr experiment we see that there are no days in the 16 year period (last 8 years in the forecasts from 1985 and 1995) when the mean wind in the area is westerly. By applying the momentum-flux correction, the distribution is shifted towards more westerly wind. The shift is about $0.01 \mathrm{~N} / \mathrm{m}^{2}$ that corresponds well with the applied flux correction (compared with Fig. 3a). The momentum-flux correction does not only induce a shift in the distribution of zonal wind stress, but it also broadens it, producing longer tails. The difference between Ucorr and UHcorr is small although the additional heat-flux correction broadens the distribution slightly (as an effect of the higher ENSO variability). For the UHcorr, the tail for westerlies is even longer than that of the reanalysis (more frequent westerlies in UHcorr than the reanalysis). 
Fig. 11 Inter-annual variability (standard deviation of interannual anomalies) for seasurface temperature $(\mathrm{K})$, for forecast year 3-10. a Reanalysis, b NOcorr, c Ucorr, d UHcorr (a) Reanalysis

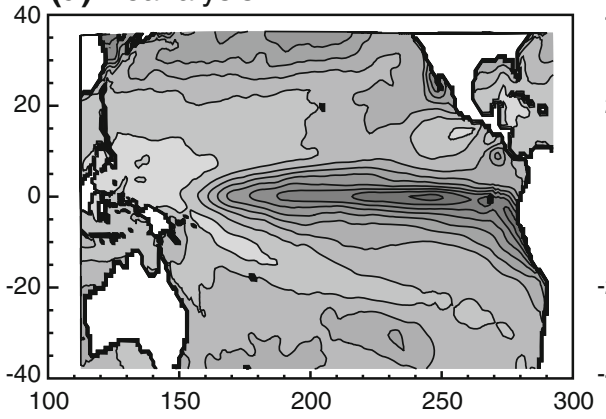

(c) Ucorr

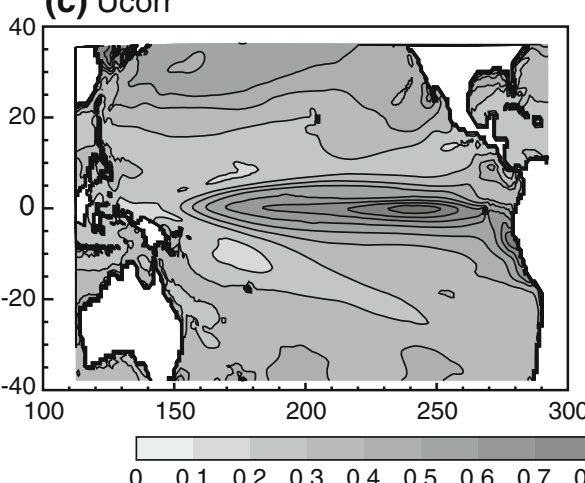

(b) NOcorr

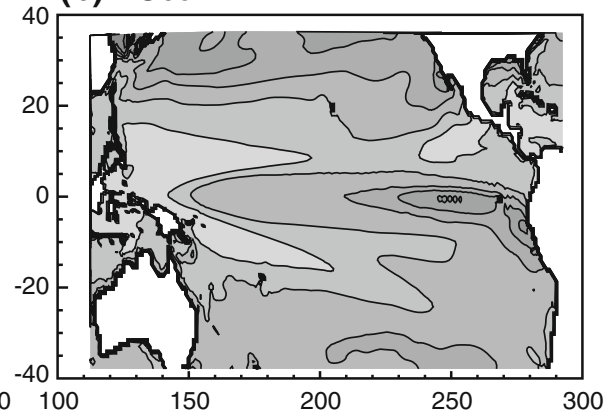

(d) UHcorr

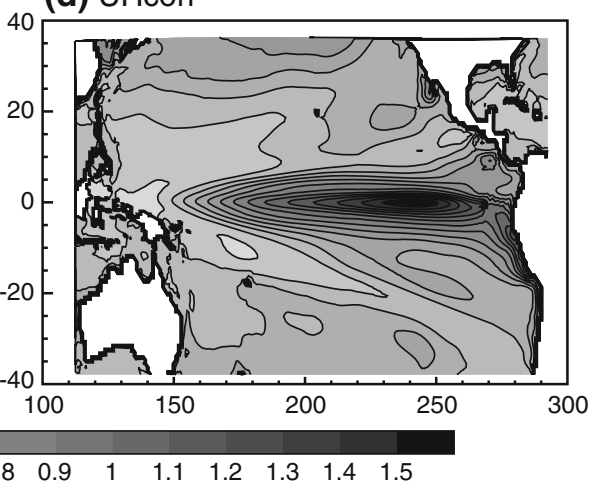

(K)

\subsection{Impact on the atmospheric variability}

The Walker circulation is the atmospheric counter-part of the equatorial oceanic circulation in the tropical Pacific, driven by the convection in the western Pacific and over the Maritime Continent. It consists of easterly winds in the lower troposphere, rising motion in the western part of the basin (connected with negative pressure anomaly at sea-level), westerlies in the upper troposphere and sinking motion in the eastern part of the basin (connected with high sea-level pressure).

Figure $12 \mathrm{~b}$ shows a histogram of the Southern Oscillation Index (SOI), based on monthly means for forecast years $3-10$. The index is defined as the pressure difference between Easter Islands $\left(27^{\circ} \mathrm{S}, 109^{\circ} \mathrm{W}\right)$ and Darwin $\left(12^{\circ} \mathrm{S}\right.$, $131^{\circ} \mathrm{E}$ ). A weak (strong) pressure gradient is the signature of El Niño (La Niña). The results show that the NOcorr forecasts are biased towards a too high pressure gradient, looking like a constant La Niña. The distribution is too narrow compared to the reanalysis, indicating that the variability is too weak. For the Ucorr (green) experiment the distribution is shifted towards a weaker gradient and is closer to the reanalysis, although the mean of the gradient is still too strong. For the UHcorr experiment (blue), the distribution agrees well with the reanalysis, both in mean and in width. The over-activity seen in the SST is not so obvious here. However, the tail on the negative side (El Niño) is longer for the UHcorr experiment (although the tail is difficult to see in the figure). The differences in variability at the surface have effects on the whole tropospheric circulation over the tropical Pacific, which is further discussed in Magnusson et al. (2011).

Figure $12 \mathrm{c}$ shows the histogram of the monthly precipitation rates for the Niño3.4 area for forecast years 3-10 with a logarithmic scale on the y-axis. During El Niño, the convection in the western Pacific moves eastward and affect this area. The $y$-axis has a logarithmic scale so that the rare events with high precipitation are highlighted. Due to the uncertainties in the precipitation in the ERA Interim (black, solid), the precipitation from GPCP (black, dashdotted) has also been plotted. The main difference between the reanalysis and GPCP is that the latter has more months with very low precipitation (less than $1 \mathrm{~mm} /$ day), while ERA Interim has more months with precipitation between 3-5 mm/day. The tails of the distributions agree well. Regarding the forecast experiments, the NOcorr has the worst results. For this experiment, the rain periods are clearly under-represented, due to the cold SST bias that suppress the convection and the fact that the forecasts have too few El Niño events.

The precipitation is much better represented in both flux-corrected experiments and the distributions agree well 
(a) Zonal wind stress in Niño4 area

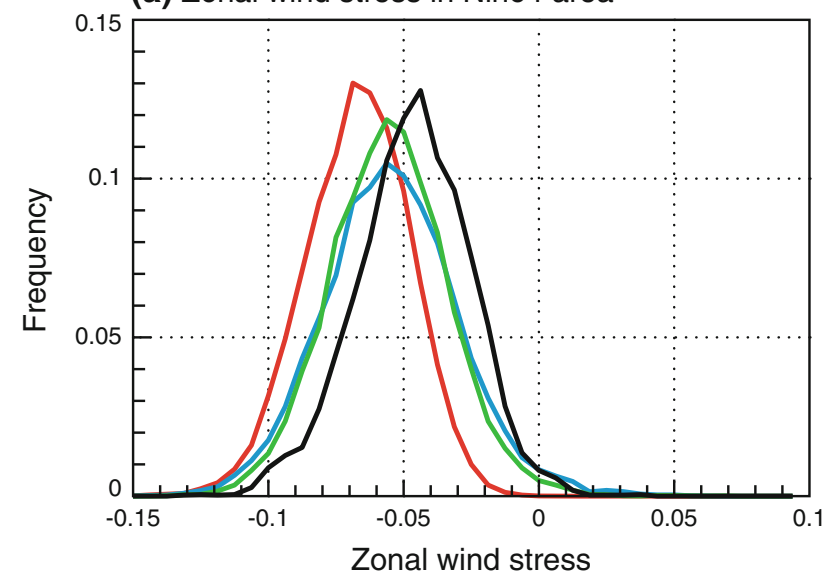

(b) Southern Oscillation Index

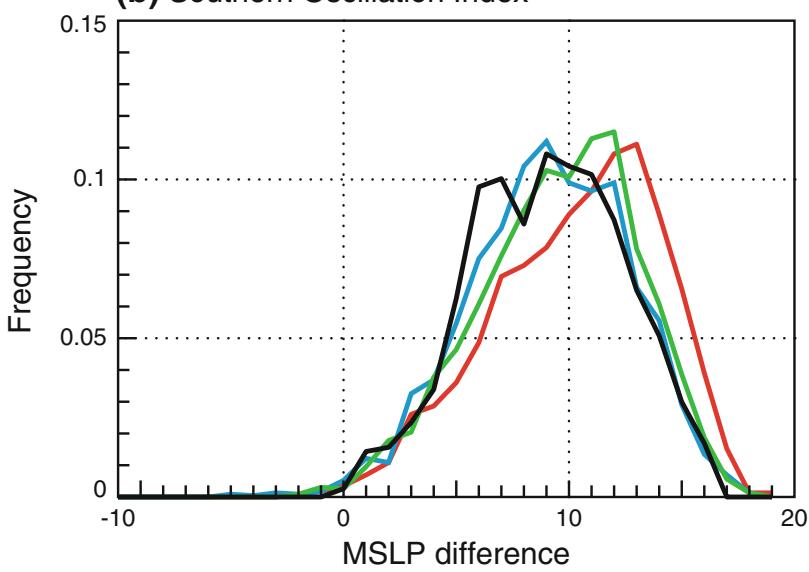

(c) Precipitation for the Niño3.4 area. GPCP for 1980-1995 (black chain-dashed)

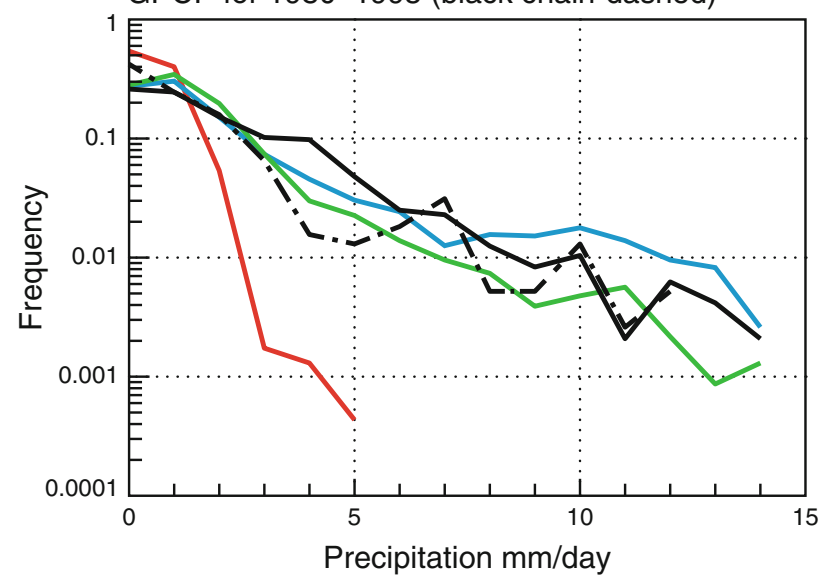

Fig. 12 Histogram of ENSO statistics. Reanalysis (black), NOcorr (red), Ucorr (green) and UHcorr (blue). a Zonal wind stress in Niño4 area, $\mathbf{b}$ southern oscillation index, $\mathbf{c}$ precipitation for the Niño3.4 area

with both GPCP and ERA Interim. However, in the UHcorr experiment, the strong precipitation are too frequent. This is connected to the over-representation of strong El Niño in the forecasts.
Figure 13 shows the DJF precipitation teleconnection pattern as a composite of warm events, defined as events when the Niño3.4 SST anomaly is stronger than half a standard deviation. The colour scale for the plots has been chosen to focus on the response in the tropics. In the reanalysis (ERA Interim) the centre of gravity for the precipitation moves eastwards during El Niño events, with a maximum to the east of the date line. In the NOcorr experiment (Fig. 13b), the precipitation response is very weak, and the centre of gravity is far to the west of the date line, explaining why in this experiment there are no strong precipitation anomalies in the Niño3.4 even during El Niño events. The precipitation pattern for Ucorr (Fig. 13c) and UHcorr (Fig. 13d) agrees well with the reanalysis (Fig. 13a) but with a too strong amplitude, especially for UHcorr, consistent with Fig. 12c.

Figure 14 shows the teleconnection pattern of positive events of the Niño3.4 SST for DJF $500 \mathrm{hPa}$ geopotential height (z500). The reanalysis shows a teleconnection pattern with a negative anomaly over northern Pacific and a positive anomaly over central North America. The pattern is reminiscent of a standing Rossby wave originating from the heating in the tropical Pacific.

Compared with the reanalysis, the NOcorr experiment yields very weak response of El Niño events and is out of phase in the northern Pacific. The erroneous pattern in z500 is consistent with the weak convective response and the wrong positioning of the heating. Ucorr shows an improved pattern in amplitude over the northern Pacific but the positive anomaly over North America is out of phase with the reanalysis, while UHcorr also get North America node fairly correct, although it overestimates the response in the tropical band.

The difference in the North America teleconnection pattern between Ucorr and UHcorr is likely to be related to difference in biases in the mean flow over northern Pacific (not shown). The heat-flux correction leads to a reduction of the systematic errors also in the free troposphere. Because the propagation of Rossby waves is dependent on the background flow (Hoskins and Karoly 1981), a wrong mean state is likely to impact the teleconnection patterns. Some of the difference could also be due to differences in the strength and position of the convection during El Niño events seen in Fig. 13. The difference in z500 teleconnection pattern for North America leads to a difference in the teleconnection pattern for the 2-m temperature, where the pattern for UHcorr is in better agreement with ERA Interim than Ucorr for this region (not shown).

Altogether, the results in this section show that the impact of correcting the mean state in the ocean also feedbacks onto the inter-annual variability of the atmosphere. 
(a) Reanalysis

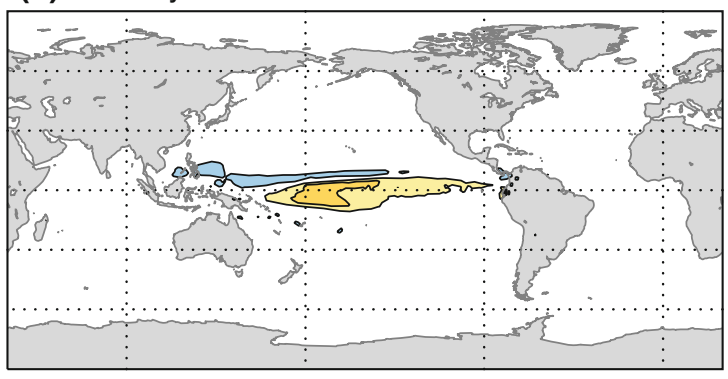

(c) Ucorr

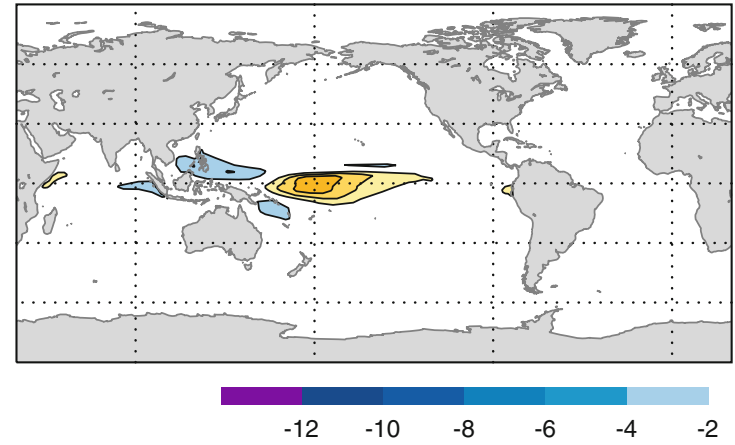

(b) NOcorr

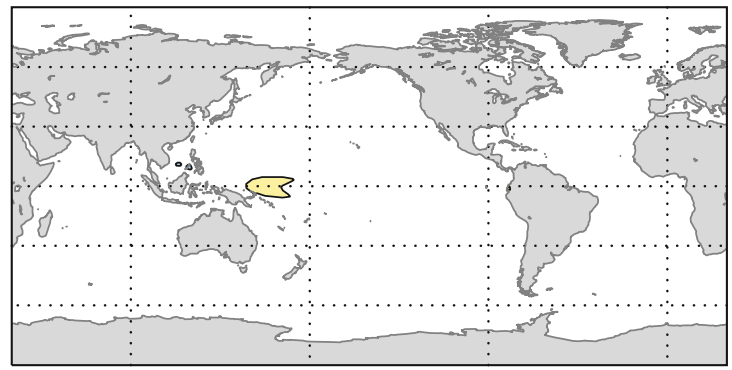

(d) UHcorr

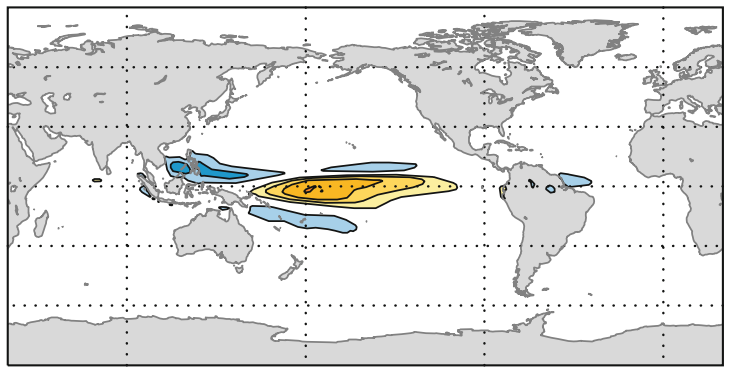

${ }^{2}$

Fig. 13 Teleconnection composite of positive events of Niño3.4 SST to total precipitation for DJF. The forecasts using forecast year 4-9 for the forecast initialised 1975-2000 and ERA Interim year 1979-2009. a Reanalysis, b NOcorr, c Ucorr, d UHcorr

(a) Reanalysis

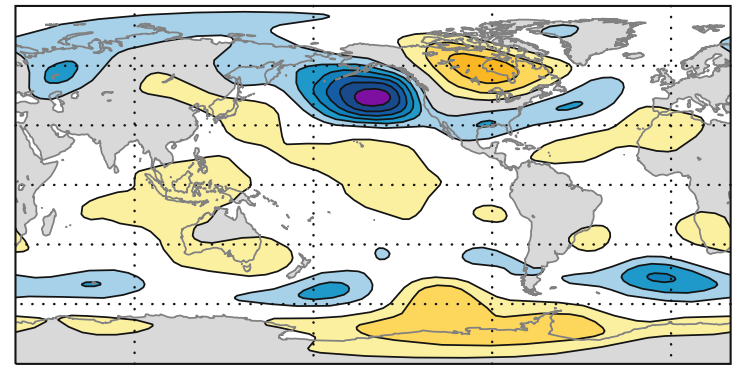

(c) Ucorr

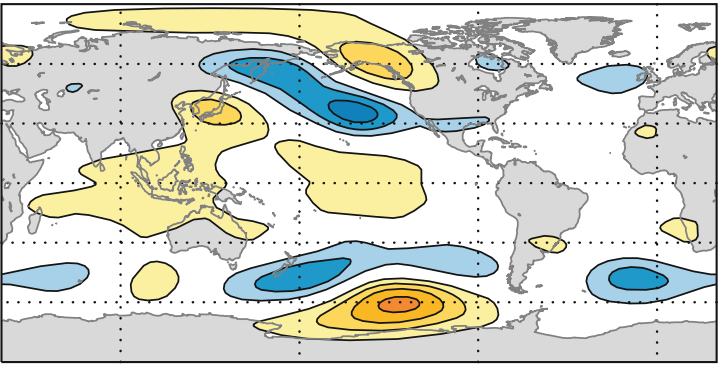

$-60$

\section{(b) NOcorr}

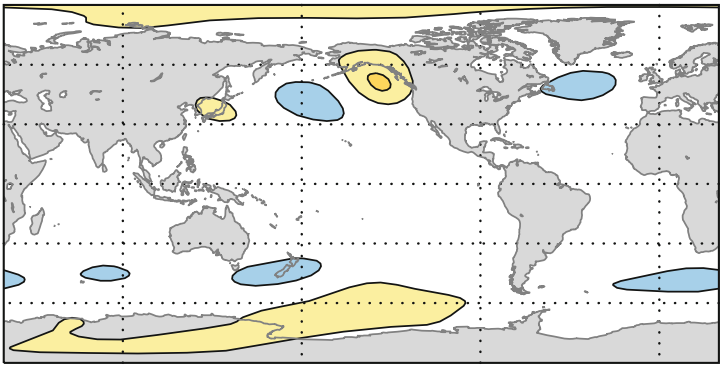

(d) UHcorr

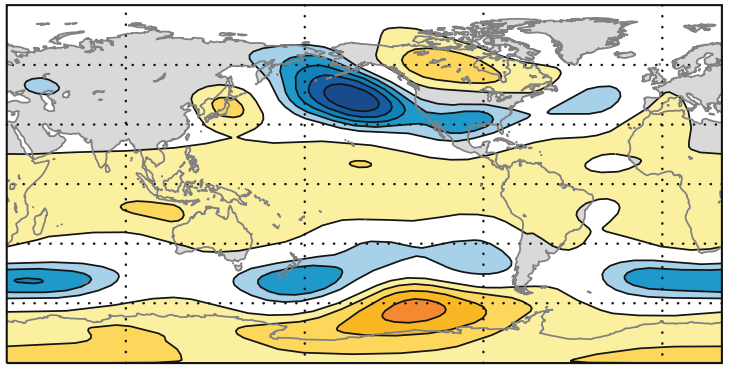

Fig. 14 Teleconnection composite of positive events of Niño3.4 SST to z500 for DJF. The forecasts using forecast year 4-9 for the forecast initialised 1975-2000 and ERA Interim year 1979-2009. a Reanalysis, b NOcorr, c Ucorr, d UHcorr 


\section{Conclusions and discussion}

In this study we have investigated the impact of the model mean state on the simulation of El Niño events. In the presence of systematic model error, the mean state and the variability of the model could differ from the observed mean state and variability. In this study we investigate the relationship between the mean state and the variability by comparing coupled-model simulations using the standard model configuration with simulations where we have attempted to remove the mean error and sampling of the seasonal cycle in the sea-surface temperature by applying flux correction.

The forecasting system used is the ECMWF IFS model coupled to the NEMO ocean model. The current model setup develops a cold bias on the seasonal time-scale, which is pronounced in the tropical Pacific due to a strong upwelling of cold water in the eastern part of the equatorial Pacific. The cold bias in the tropical Pacific is connected to a bias in the zonal wind (strong easterly winds). It is shown that a part of the wind bias is present in model runs with strong constrain to observed SST, suggesting that the origins of the wind bias is in the atmospheric model, and that the bias is enhanced in the coupled system by a basic positive feedback mechanism especially in the western Pacific.

We have used flux correction in order to change the model climate towards the observed mean state. A set of decadal coupled integrations have been conducted using three different strategies. One strategy only uses momentum-flux correction and another uses both momentum and heat-flux correction. In the third strategy the model mean state is left uncorrected, and the integrations have been initialised using anomaly initialisation. An alternative approach could have been to use full initialisation strategy, as is currently used in seasonal forecasting, with a model drift in the first months into the integrations. However, the results for full initialisation and anomaly initialisation regarding the variability should be similar after the model has drifted to its climatology.

Results show that by applying momentum-flux correction it is possible to remove a part of the cold bias in the tropical Pacific, by reducing the westward penetration of the cold tongue, which is equivalent to reducing the region where the upwelling is active. This result shows the importance of having the correct winds in order to obtain the correct SST mean state. With the combination of heat and momentum-flux correction most of the SST bias is removed, and this is the basic test and expected result of a successful flux correction.

The results show that the ENSO related variability is very different in the different experiments. The free coupled model showing very weak variability while in the flux corrected experiments, where both the mean state and seasonal cycle have been corrected, the inter-annual variability is very much improved. The uncorrected model shows a too strong seasonal cycle in the zonal wind stress and thermocline, while the flux-corrected experiments show about the right seasonality in wind and thermocline. It has been shown in the literature (Guilyardi 2006) that models with a strong seasonal cycle tend to show weak ENSO variability, and our results fit this description well. A plausible explanation for the connection between a strong seasonal cycle and weak ENSO is given in Fedorov and Philander (2001), where a fast (annual) and local mode of variability was favoured by wind-induced upwelling. Our results show that the momentum-flux correction is responsible for shifting the variability from an annual mode to inter-annual time scales, but it remains unclear if this is achieved by reducing the cold phase in the Eastern Pacific, or by favouring the displacements of the warm pool.

In the heat and momentum-flux corrected experiment, the inter-annual variability seems to be too large compared to observed variability and for some ensemble members the oscillation seems to be regular, with an ENSO period length of 3 years. This is not the case for all forecasts, but is seems like several ENSO cycles with high amplitude appear after each other. The issue with perpetual ENSO is not new and is discussed e.g. in Misra et al. (2007). The reason for these multiple ENSO-cycles may lay on a too strong subsurface wave dynamics, as discussed in Jin (1997b) — we found differences in the structure of the thermocline between the heat and momentum-flux corrected experiment and the reanalysis, probably due to a too diffusive ocean model, which could influence the wave dynamics. Another reason for the differences in variability could be due to a lack of "stochastic" westerly wind bursts, which could happen if, for instance, the intra-seasonal variability is weak in the model.

While our experiments indicate that the momentum-flux correction is instrumental for the change in the ENSO variability, it is not possible to say if this improvement comes from correcting the mean state or/and the correction of the seasonal cycle. For instance, we can not confirm nor refute the suggestion by Fedorov and Philander (2001) that a change in mean zonal wind stress should be enough to change the relation between annual (fast) mode and interannual (slow) mode, without explicit modification of the seasonal cycle. Our experiments do not contradict either the results by Pan et al. (2011) and Manganello and Huang (2009), where the correction of the mean state by applying only an annual heat-flux correction improves both the seasonal cycle and ENSO variability. Further experiments with only heat-flux correction and without seasonal cycle would be needed to contradict or confirm any of these previous results. However, the results definitively show 
that the momentum-flux correction without any heat-flux correction is able to change the ENSO variability.

The increased variability in SST has also a strong influence on the atmospheric variability, for example in the impact on the Southern Oscillation index. The use of flux correction also has a large affect on the precipitation amounts in the tropical Pacific. By improving the cold bias, the precipitation increases in the mid of the Tropical Pacific and the variability pattern shows more similarities with observed precipitation. Also teleconnections to other regions around the Pacific are better simulated with when heat and momentum corrections are applied, likely because the mean state of the troposphere is also corrected.

Altogether, the results shown here illustrate the delicate balance needed in the coupled model to obtain the correct ENSO properties (time scale, propagation, amplitude of SST) as well as atmospheric response to ENSO in terms of precipitation and teleconnection patterns. Indeed, it is only with the UHcorr experiment, that clearly overestimates the ENSO variability and the precipitation response, that the North America teleconnection pattern is best represented.

The variability is not only important for the simulations of the ENSO events but also create a sufficient ensemble spread. If the model variability is too low the ensemble spread will be low as well (Bengtsson et al. 2008) and the ensemble becomes over-confident.

These results are important for the choice of forecast strategies for seasonal and decadal forecasts. This study shows that the biased mean state severely affects the ENSO variability and teleconnections. By applying anomaly initialisation, the systematic errors are already present in the initial conditions of the forecast, and the errors in the variability will deteriorate results already in the early forecast ranges. If using full initialisation (initialised with the observed state), the model will eventually drift to its own climate. In this case there is the added difficulty that errors in the variability will change as a function of lead time, and in the case of strong nonlinearities, even the estimation of the bias (for a-posteriori bias correction) can be difficult. For the choice of forecast strategy, practical considerations in calculating the climatologies (applicable for anomaly initialisation), the correction required (flux correction) and time-dependent bias correction (full initialisation) are of importance. A companion paper (Magnusson et al. 2012) discusses the forecast strategies in more detail, with focus on the forecast skill.

It may be possible that there is no such as thing as the best forcast strategy: different CGCMs have different biases, and a forecast strategy that works well for one model may be detrimental for another. In Spencer et al. (2007) the model had a cold SST bias in the equatorial Pacific and a too strong inter-annual variability, while the model in this study had a cold bias and too low inter-annual variability.
In our study we have traced a large part of the bias in the equatorial Pacific to a wind bias, which makes the momentum-flux correction relevant, while the momentumflux correction in Spencer et al. (2007) had a minor impact on the inter-annual variability.

The results in this study show that it is difficult to interpret results regarding a change in ENSO variability for future climate if the model itself is biased. A change in the ENSO activity could then either be due to climate change or a nonlinear effect of the systematic error in the model. However, in order to predict strong ENSO events, it is needed that the model could simulate such a amplitude of the variability. This study concludes that a correct mean state is needed to allow such a variability.

Acknowledgments We would like to acknowledge Kristian Mogensen, Tim Stockdale and Sarah Keeley for help during the project. This work was funded by the European Commission's 7th Framework Programme, under Grant Agreement number 226520, COMBINE project. We would also like to thank Rob Hine and Anabel Bowen for help with the preparation of the figures for this report and the two anonymous reviewers whose comments helped us to improve this manuscript.

Open Access This article is distributed under the terms of the Creative Commons Attribution License which permits any use, distribution, and reproduction in any medium, provided the original author(s) and the source are credited.

\section{References}

Balmaseda MA, Anderson DLT (2009) Impact of initialization strategies and observations on seasonal forecast skill. Geophys Res Lett 36:L1701

Balmaseda MA, Davey MK, Anderson DLT (1995) Decadal and seasonal dependence of ENSO prediction skill. J Clim 8:2705-2715

Balmaseda MA, Mogensen K, Molteni F, Weaver AT (2010) The NEMOVAR-COMBINE ocean re-analysis. COMBINE technical report 1, FP7 COMBINE project

Bengtsson LK, Magnusson L, Källén E (2008) Independent estimations of the asymptotic variability in an ensemble forecast system. Mon Weather Rev 136:4105-4112

Bjerknes J (1969) Atmospheric teleconnections from the equatorial Pacific. Mon Weather Rev 97:163-172

Dee DP et al (2011) The ERA-Interim reanalysis: configuration and performance of the data assimilation system. Q J R Met Soc 137:553-597

Eisenman L, Yu I, Tziperman E (2005) Westerly wind bursts: ENSO's tail rather than the dog? J Clim 18:522-5238

Fedorov AV, Philander SG (2001) A stability analysis of tropical ocean-atmospheric interactions: bridging measurements and theory of El Niño. J Clim 14:3086-3101

Guilyardi E (2006) El Nino-mean state-seasonal cycle interactions in a mutil-model ensemble. Clim Dyn 26:329-248

Guilyardi E, Wittenberg A, Fedorov A, Collins M, Wang C, Capotondi A, Oldenborgh GJv, Stockdale T (2009) Understanding El Nino in ocean-atmosphere general circulation models. Bull Am Meteorol Soc 90:324-340 
Hoskins B, Karoly DJ (1981) The steady linear response of a spherical atmosphere to thermal and orographic forcing. J Atm Sci 38:1179-1196

Huffman GJ, Adler DT, Bolvin DT, Gu G (2009) Improving the global precipitation record: GPCP Version 2.1. Geophys Res Lett 36:L17 808

Jin EK, et al (2008) Current status of ENSO prediction skill in coupled ocean-atmosphere models. Clim Dyn 31:647-664

Jin F-F, (1997a) An equatorial ocean recharge paradigm for ENSO. Part I: conceptual model. J Atm Sci 54:811-829

Jin F-F (1997b) An equatorial ocean recharge paradigm for ENSO. Part II: a stripped-down coupled model. J Atm Sci 54:830-847

Keenlyside NS, Latif M, Jungclaus J, Kornblueh L, Roeckner E (2008) Advancing decadal-scale climate prediction in the North Atlantic sector. Nature 453:84-88

Kessler WS, Kleeman R (2000) Rectification of the Madden-Julian oscillation into the ENSO cycle. J Clim 13:3560-3575

Kröger J, Kucharski F (2011) Sensitivity of ENSO characteristics to a new interactive flux correction scheme in a coupled GCM. Clim Dyn 37:119-137

Lengaigne M, Guilyardi E, Boulanger JP, Menkes C, Delecluse P, Inness P, Cole J, Slingo J (2004) Triggering of El Nino by westerly wind events in a coupled general circulation model. Clim Dyn 23:601-620

Madec G (2008) NEMO reference manual, ocean dynamics component: NEMO-OPA. Note du Pole de Modelisation 27, Institut Pierre-Simon Laplace (IPSL), France

Magnusson L, Balmaseda MA, Corti S, Molteni F, Stockdale T (2012) Evaluation of forecast strategies for seasonal and decadal forecasts in presence of systematic model errors. Clim Dyn (submitted)

Magnusson L, Balmaseda MA, Molteni F (2011) On the dependence of ENSO simulation on the coupled model mean state. Technical Memorandum 658, ECMWF

Manganello JV, Huang B (2009) The influence of systematic errors in the Southeast Pacific on ENSO variability and prediction in a coupled GCM. Clim Dyn 32:1015-1034

Misra V, et al. (2007) Validating and understanding the ENSO simulation in two coupled climate models. Tellus A 59:292-308
Molteni F, et al. (2011) The new ECMWF seasonal forecast system (System 4). Technical Memorandum 656, ECMWF

Palmer T, Buizza R, Doblas-Reyes F, Jung T, Leutbecher M, Shutts J, Steinheimer GM, Weisheimer A (2009) Stochastic parametrization and model uncertainty. Technical Memorandum 598, ECMWF

Pan X, Huang B, Shukla J (2011) Sensitivity of the tropical Pacific seasonal cycle and ENSO to changes in mean state induced by a surface heat flux adjustment in CCSM3. Clim Dyn 37:325-341

Pierce DW, Barnett TP, Tokmakian R, Semtner A, Maltrud M, Lysne J, Craig A (2004) The ACPI project, element 1: initializing a coupled climate model from observed conditions. Clim Change 62:13-28

Reynolds RW, Rayner TM, Smith DC, Stokes DC, Wang W (2002) An improved in situ and satellite SST analysis for climate. J Clim 15:1609-1625

Schneider EK, Huang B, Zhu Z, DeWitt DG, Kinter JL, Kirtman BP Shukla J (1999) Ocean data assimilation, initialisation, and predictions of ENSO with a coupled GCM. Mon Weather Rev 127:1187-1207

Smith D, Cusack A, Colman A, Folland C, Harris G (2007) Improved surface temperature predictions for the coming decade from a global circulation model. Science 317:796-799

Spencer H, Sutton R, Slingo JM (2007) El Nino in a coupled climate model: sensitivity to changes in mean state induced by heat flux and wind stress corrections. J Clim 20:2273-2298

Uppala SM et al (2005) The ERA-40 re-analysis. Q J R Meteorol Soc 131:2961-3012

Vitart F, Balmaseda MA, Ferranti L, Anderson DLT (2003) Westerly wind events and the 1997/1998 El Nino event in the ECMWF seasonal forecasting system: a case study. J Clim 16:3153-3170

Wang B, An SI (2002) A mechanism for decadal changes of ENSO behavior: roles of background wind changes. Clim Dyn 18:475-486

Wang C, Picaut J (2004) Understanding ENSO physics-a review. Earth's climate: the ocean-atmosphere interaction, geophysical monograph series, vol 147. AGU, Washington, DC 